Estudios Constitucionales, Año 16, No 1, 2018 pp. 129-166

ISSN 07180195

Centro de Estudios Constitucionales de Chile Universidad de Talca

"El control de convencionalidad: ¿̨un acto racional o irracional"

Álvaro Mesa Latorre

\title{
EL CONTROL DE CONVENCIONALIDAD: ¿UN ACTO RACIONAL O IRRACIONAL?
}

THE CONVENTIONALITY CONTROL: ¿A RATIONAL OR IRRATIONAL ACT?*

\author{
Álvaro Mesa Latorre ${ }^{* *}$ \\ Universidad Mayor \\ alvaromesalatorre@gmail.com
}

RESUMEN El presente trabajo, realiza una exploración del concepto control de convencionalidady su ejercicio. Dicho examen se esculpe desde la perspectiva de la razón (entendida y enmarcada, como facultad, capacidad, fundamento). Es decir, si la creación del concepto aludido, como su práctica, constituyen en definitiva un acto racional o irracional. Ello, debido a la discusión actual, tanto en doctrina como en la jurisprudencia, en cuanto a que dicha noción y uso, estaría fuera de los límites racionales y normativos, dados a la Corte Interamericana de Derechos Humanos y lo mismo a los tribunales nacionales de cada pais. Constituiría dicho control en sus primeras etapas-concepto y ejercicio-un absurdo, una confusión de derecho. El ensayo entonces, en esa linea, aborda la idea de racionalidad e irracionalidad y su enlace con el control de convencionalidad (noción, ejercicio). Esta relación apunta además, a indagar la génesis histórica que permite su aparición y la evolución de dicho control, en la jurisprudencia de la Corte citada. Para finalizar con un catastro de las críticas y observaciones más relevantes realizadas.

ABSTRACT: The current paper goes through an exploration about the concept of the conventionality control and his practice. These words are taken from the view of the reason (understood and demarcated as a faculty, capacity, fundament). Meaning, if the use of the conventionality control establishes a rational or irrational act. The origin of this thoughts rely on the current discussion in both doctrine and jurisprudence and if the practice of those are beyond the normative boundaries established by the Inter-American Court of Human Rights and the local courts of each country. This concept in their

\footnotetext{
* Artículo recibido el 6 de julio de 2017 y aprobado el 6 de diciembre de 2017.

** Licenciado en Ciencias Jurídicas, Universidad de Valparaíso. Abogado. Ministro de Ilma. Corte de Apelaciones de Temuco. Magíster ( ) en Derecho, Universidad Católica de Temuco. Postítulo en Reforma Procesal Penal y Litigación Oral, Universidad de Magallanes. Postítulo en Derecho Internacional de los Derechos Humanos, Universidad de Chile. Curso anual en Derecho Constitucional, Instituto Iberoamericano de Altos Estudios Judiciales. Postítulo Recurso de Protección: Dogmática y Jurisprudencia, Universidad de Chile. Postítulo en Protección Judicial en Derechos de los Niños, Universidad Diego Portales. Postítulo en Marco Jurídico Internacional de la libertad de expresión, acceso a la información pública y protección de periodistas, Unesco - Journalism in the Americas at the University of Texas at Austin. Profesor titular de Teoría Política y Derecho Constitucional y Director del Centro de Estudios Constitucionales y Administrativos, Facultad de Humanidades, Escuela de Derecho, Universidad Mayor, sede Temuco, Chile. alvaromesalatorre@ gmail.com.
} 
first stages -control and practice - will constitute something without sense, a misconception of the law. The essay then, touches the idea of rationality and irrationality and their connections with the conventionality control (practice, notion). This relation points also to inquire about the historical genesis that allows the appearance and evolution of this control and the jurisprudence of the Court previously cited. To finalize with a cadaster of the most important reviews and observations.

PALABRAS CLAVE: Control de convencionalidad, Corte, irracionalidad, jurisprudencia, racionalidad. KEYWORDS: Conventionality control, Court, irrationality, jurisprudence, rationality.

\section{INTRODUCCIÓN}

Los derechos humanos, han permitido (con sus luchas, logros y retrocesos) fijar un estándar mínimo de convivencia civilizada. Este consiste en el respeto de los derechos y libertades reconocidos en cada jurisdicción; y a garantizar en ese mismo lugar y competencia, su libre y pleno ejercicio, sin discriminación alguna ${ }^{1}$. Estos derechos nos están dando siempre una franja, un campo infranqueable de racionalidad. En todo momento, nos exhortan a reflexionar, a fundamentar nuestras actuaciones. Son una muralla potente frente a la arbitrariedad. Ahora bien, en la mirada anterior, lo que se indaga en este acotado artículo, es observar cómo ha sido la actuación del conjunto de Estados nacionales en Latinoamérica para difundir, tomar conciencia y proteger los derechos aludidos. Luego en específico, si el avance en la protección de los derechos humanos ha mantenido una coherencia en el tiempo y si ello, permitió que surgiera como Jurisprudencia de la Corte Interamericana de Derechos Humanos (en adelante Corte IDH, Corte) el control de convencionalidad (en este trabajo, control cv). Más preciso aún, si en ese caminar, y en lo concreto en la creación y ejercicio del control cv, ha existido racionalidad o irracionalidad. En definitiva si la Corte IDH y los tribunales nacionales en estas primeras etapas se han mantenido atados a esa franja de racionalidad o la han abandonado. Para cumplir esa meta, el ensayo se divide en siete capítulos: Capítulo I, se aborda en forma sintética una noción de racionalidad e irracionalidad. Capítulo II, se realiza un repaso de la génesis histórica que ha tenido la difusión y protección de los derechos humanos. Capítulo III, se investiga la evolución jurisprudencial del control de convencionalidad en sus primeras etapas. Capítulo IV, se analiza la noción de control de convencionalidad en estas iniciales etapas. Capítulo V, se repasan las observaciones, alcances y críticas más relevantes que han manifestado los autores sobre la noción y la

1 Convención Americana sobre Derechos Humanos (1969). Artículo 1.1. 
aplicación del control de convencionalidad en sus primeras etapas. Capítulo VI, se realiza un examen del marco de racionalidad. Finalmente, en el Capítulo VII, se puntualizan unas últimas reflexiones.

\section{RACIONALIDAD E IRRACIONALIDAD}

\section{I.1. Aproximación}

Como apunta Pedrals, nuestras decisiones no se basan en lo que una racionalidad plenamente desplegada requeriría, pues a nuestro poder decisional le damos un marco incompleto. Para decidir completamente se necesitaría una cantidad gigantesca de nuestros recursos cognitivos ${ }^{2}$. Como un ejemplo de ello, tenemos, que en la segunda mitad del siglo XX la galaxia (Vía Láctea), se equiparó al cosmos; nadie hubiera imaginado que el cosmos estuviera compuesto de múltiples galaxias. La mente humana todavía no era consciente de sus descomunales dimensiones. Hoy se estima que existen más de cien mil millones de galaxias, cada una compuesta por más de cien mil millones de estrellas ${ }^{3}$. Ahora bien, una acción racional consiste en utilizar los medios adecuados para lograr un fin deseado. Es decir, lograr ese fin con los mejores medios, a los menores costos ${ }^{4}$. En esa perspectiva, la noción de razón tiene varias aristas, pero como señalamos en el resumen, la hemos enmarcado para este ensayo en tanto, idea de facultad, capacidad y de fundamento. Es entonces, esta capacidad de argumentar, formar conceptos, explicar, comprender y ordenar ${ }^{5}$. La razón es facultad pensante, que permite alcanzar el conocimiento y llegar al reino de las ideas. También alude al fundamento, esto es, la razón explica por qué algo es como es y no de otro modo ${ }^{6}$. Por su lado, razonable, distingue a lo arreglado, justo, conforme a razón 7 . En las

2 Pedrals (2014), pp. 436-437.

3 Solé (2016), pp. 109-110.

4 González (2000), pp. 27-26.

5 Ibídem, p. 333.

${ }^{6}$ FerRater (2007), pp. 300-302. El autor realiza un largo desarrollo, del concepto de razón en la historia de la filosofía. Destaca tres: El primero, como la facultad atribuida al hombre y que lo distingue de los demás, de la serie animal. El segundo, la razón como equivalente a fundamento. El tercero un decir. Un decir que se funda en el modo ser racional.

7 Real Academia de la Lengua (2001), p. 1904. 
antípodas está la noción de irracional. Algo ajeno a la razón ${ }^{8}$. O bien, aquello que carece de razón. Opuesto a la razón o que cabe fuera de ella. Es decir, la irracionalidad, es el comportamiento o expresión descabellados, falto de racionalidad?

\section{I.2. Filosofía general}

El pensamiento de Aristóteles es una placa tectónica, pues a través de él conocemos conceptos claves en el desarrollo de las ideas, por ejemplo consecuencia, lógica, contradicción, falacia, prudencia, entre otras ${ }^{10}$. Pues bien, en este deambular de racionalidad (buscar, criticar, pensar), con el racionalismo de Descartes ${ }^{11}$ (pienso y por lo tanto existo) aprendemos que las premisas y consecuencias se siguen necesariamente, construyendo un cuerpo de ideas sólido y compacto. Pero esto en realidad, sólo tiene validez en la mente de Descartes; pues respecto a la demostración efectiva y objetiva de algo exterior y real carece de toda validez. Lo cierto es que la filosofía cartesiana se mueve en un círculo cerrado y tiene mucho de autista $^{12}$. Por ello Kant explica que el pensamiento no consiste en una percepción pasiva de los datos suministrados por los sentidos, sino que son las facultades del sujeto cognoscente las que permiten que haya conocimiento. Lo realiza por medio de facultades (papel receptivo por parte de la sensibilidad; facultad de registrar impresiones sensibles o intuiciones); y el papel interpretativo del entendimiento (facultad de los conceptos) ${ }^{13}$. Ahora bien, como explica Torretti (uno de los mayores expertos en idioma español sobre Kant), la razón en sentido estricto, es la facultad de pensar y exigir lo incondicionado ${ }^{14}$. Ligado a lo anterior, ya en el

8 FerRater (2007), p. 207.

9 Real Academia de la Lengua (2001), p. 1302.

10 Correia (2016), p. 6.

11 Ferrater (2007), p. 300. Enseña el publicista, que el racionalismo básicamente puede entenderse de 3 formas: a) Teoría según la cual la razón equiparada con la facultad pensante, es superior a la emoción y a la voluntad (Racionalismo psicológico); b) Doctrina según la cual el único órgano adecuado del conocimiento es la razón. Todo conocimiento verdadero tiene origen racional (Racionalismo gnoseológico o epistemológico); c) Teoría que indica que la realidad es de carácter racional (Racionalismo metafísico). En todo caso, las significaciones se han combinado con frecuencia.

12 SOLÉ (2015), pp. 14-15.

13 Ibídem, pp. 15-16.

14 Torretti (2013), p. 591. El filósofo explica que la razón humana exige lo incondicionado, cada vez que debe enfrentar una serie de condiciones. Exige la razón que nos remontemos de causa en causa, hasta encontrar una primera causa incausada. 
siglo XX, como expresó Wittgenstein, lo que el sujeto conoce como el mundo, le está dado por el lenguaje ${ }^{15}$. A lo largo de toda nuestra vida somos adiestrados en el uso del lenguaje, en sus reglas ${ }^{16}$. En este sentido, la Corte IDH utiliza el lenguaje de los derechos humanos que ha aprendido por décadas; y al realizar el control cv establece una relación entre la Convención Americana sobre Derechos Humanos (en adelante Convención, $\mathrm{CADH}$ ) y los Estados nacionales, para la defensa y protección de dichos derechos. De esta forma se puede vislumbrar incipientemente que el control cv, vendría a ser un ejercicio específico de la razón y una concreta relación entre los sujetos, el lenguaje y su mundo.

Si no estuviéramos conformes con las precedentes cavilaciones, Habermas acota, que la expresión racional supone una estrecha relación entre racionalidad y saber. Pero lo cierto es, que la racionalidad tiene menos que ver con el conocimiento o con la adquisición de conocimientos, que con la forma que los sujetos capaces de lenguaje y acción hacen uso de ese conocimiento ${ }^{17}$. Profundiza explicando, que en los contextos de comunicación (pertinente para este artículo) no sólo llamamos racional a quien hace una afirmación y es capaz de defenderla frente a un crítico, aduciendo las evidencias pertinentes, sino que también llamamos racional aquel que sigue una norma vigente y es capaz de justificar su acción frente a un crítico interpretando una situación dada, a luz de expectativas legítimas de comportamiento $^{18}$. Puntualiza, que la racionalidad ${ }^{19}$ puede entenderse como una disposición de los sujetos capaces de lenguaje y de acción. Se manifiesta en formas de comportamiento para las que existen en cada caso buenas razones. Esto significa que las emisiones o manifestaciones racionales son accesibles a un enjuiciamiento objetivo. Cabe precisar en cualquier caso, que se puede distinguir entre un uso racional y un uso irracional de estándares, con que los miembros de una comunidad de cultura y de unas comunidades de lenguaje interpretan sus necesidades. Es lo que explica Habermas, con el siguiente ejemplo: desear simplemente una taza de lodo es irracional, porque es menester alguna razón más para desearla. Desear una taza de lodo, porque uno desea aspirar su rico olor a río, es racional. No se necesita ninguna razón más, para desear gozar de su rico olor a río;

15 Carmona (2015), p. 74.

16 Ibídem, p. 89.

17 Habermas (1998), p. 24.

18 Ibídem, p. 33.

19 Ibídem, p. 42. 
ya que caracterizar lo que se desea como "gozar de su rico olor a río" significa dar una razón aceptable para desearlo, y, por tanto, ese deseo es racional20. También sería irracional a propósito del contexto de derecho, el caso citado por Cecilia Medina. El profesor Van Hoof, escribió en 1986 que en Holanda, a propósito de la Convención Europea de Derechos Humanos (comenzó a funcionar 1953) que en los años sesenta, un juez de primera instancia había rechazado una alegación en que se invocaba dicho Pacto, basado en que él desconocía la existencia de un tratado semejante y que además, este tampoco estaba en su biblioteca ${ }^{21}$. En este caso la Corte IDH ha recogido ese uso del lenguaje por décadas y le ha dado una utilización a ese conocimiento que no se aparta de un acto racional.

\subsection{Filosofía del derecho}

A propósito de la racionalidad de las partes, Rawls en su Teoría de la Justicia, alude al concepto de racionalidad deliberativa. Esto es, una persona racional, detendrá su deliberación sólo hasta que haya encontrado lo mejor que se le ofrece. Una persona se conduce de modo irracional cuando su falta de disposición a pensar qué es lo mejor (o lo satisfactorio) que pudo hacer, le induce a errores que, si se detuviese a considerarlo, reconocería, que si lo hubiera reflexionado, habría podido impedirlo22. En estricto sentido no habría modo de sobrepasar la racionalidad deliberativa ${ }^{23}$. En una idea ya más concreta de nuestra hipótesis, la dogmática de los derechos humanos, como disciplina práctica, apunta en última instancia a la fundamentación racional de concretos juicios de deber ser, concernientes a esos derechos ${ }^{24}$. Sí, es verdad que hay muchas discusiones, como por ejemplo Scheuner utiliza con respecto a los derechos fundamentales 21 expresiones con connotaciones teóricas estructurales, ejemplo: garantía de libertad, principios de conformación social, elementos de ordenación social entre otros ${ }^{25}$. En la misma perspectiva de los autores anteriores, Alexy indica que es racional practicar las fundamentaciones jurídicas como un juego de

\footnotetext{
20 Ibídem, p. 35.

21 Medina (1990), p. 10.

22 RaWls (2006), p. 379.

23 Ibídem, p. 506.

24 Alexy (2008), p. 22.

25 Ibídem, p. 24.
} 
razones a favor y en contra. Ahora bien, que a partir de una estructura racional de fundamentación se extraigan algunos elementos y se apliquen de una manera irracional, es algo que no constituye una razón para renunciar a esa estructura racional de fundamentación ${ }^{26}$. Para tener un buen resultado, Alexy acota, que hay que transitar a un marco de modelo procedimental. Destaca el procedimiento judicial. En este, es posible observar argumentación y decisión. Además está institucionalizado, es de creación del derecho, garantiza considerable racionalidad práctica. Procedimiento judicial, que necesariamente, se encuentra vinculado a la ley, a los precedentes judiciales y la dogmática. Esta vinculación tiene como consecuencia una reducción considerable de la inseguridad relati$\mathrm{va}^{27}$. Precisando en todo caso que el discurso iusfundamental, al igual que el discurso jurídico en general, comparte la inseguridad relativa a los resultados que tiene el discurso práctico general. Por lo tanto, es inevitable la apertura del sistema jurídico provocado por los derechos humanos; pero es una apertura de tipo calificado. No es una apertura en sentido de arbitrariedad o de la mera decisión. La argumentación iusfundamental tiene cierta firmeza, por medio de las reglas y formas de la argumentación práctica general y de la argumentación jurídica. La argumentación iusfundamental que se lleva a cabo sobre esta base, es estructurada racionalmente. No tiene nada de irrazonable que un Tribunal Constitucional no sólo argumente, sino que también decida ${ }^{28}$. En ese sentido no tendría nada de irracional que la Corte IDH creara jurisprudencialmente muchos institutos jurídicos -a partir de sus razonamientos motivados- entre ellos el control cv.

\section{SÍNTESIS}

La idea de racionalidad alude a un trabajo reflexivo, crítico, decantado. Por su lado la filosofía del derecho, lo que propone es buscar siempre nuevos métodos y/o argumentaciones que nos permitan tomar las mejores decisiones (racionalidad deliberativa) y encontrar resultados para cada caso, dando siempre garantías de no arbitrariedad.

26 Ibídem, p. 458.

27 Ibídem, pp. 487-488.

28 Ibídem, pp. 508-509. 


\section{BREVE GÉNESIS HISTÓRICA}

Podemos indicar con cierta precisión, que acabada la barbarie de la Segunda Guerra Mundial, la comunidad internacional tomará conciencia de la importancia de hacer valer los derechos humanos en el orden internacional. Iniciándose un proceso con la Carta de Naciones Unidas de 1945. Fijando estándares universales en cuanto alcance de los derechos humanos. La primera regulación normativa vendría con la Declaración Universal de Derechos Humanos de 1948, para luego continuar sin retroceso con la adopción de múltiples tratados sobre derechos humanos ${ }^{29}$. Es decir, ha existido un nivel de positivación que los Estados han venido exhibiendo en materia de derechos humanos, en las diferentes formas de creación del derecho, partiendo por la fase constitucional ${ }^{30}$. En esa ilación y en el campo del derecho internacional, es posible vislumbrar, que este atraviesa por un proceso de humanización y se manifiesta en la subjetividad del individuo que detenta derechos y obligaciones derivados de normas internacionales, y es además capaz de incoar responsabilidad internacional activa, por la violación de sus derechos y responsabilidad pasiva, cuando es él el que viola las normas internacionales, cometiendo un crimen internacional ${ }^{31}$. Desde esos fundamentos, ya Spiropoulos en $1928^{32}$, señaló que la gradual emancipación del individuo de la tutela del Estado todopoderoso no es más que una cuestión de tiempo, por imponerse como consecuencia necesaria de la evolución de la organización internacional de los nuevos tiempos. El individuo debe así, ser capaz de defender por sí mismo sus derechos en el plano internacional, independientemente de toda tutela de su Estado y aun contra el propio Estado.

En el panorama regional, la preocupación de los Estados nacionales por la protección de los derechos humanos se mostró de manera clara en forma temprana. Así, en el sistema interamericano, surgió cuando en marzo de 1948, 21 Estados adoptaron la Carta de la Organización de Estados Americanos (OEA). Cuyo espíritu fue sentar un orden de paz y de justicia, y recalcar la centralidad del ser humano en la organización de la sociedad. Luego nacerá en agosto de 1948 (antes que la Declaración Universal citada) la Declaración Americana de Derechos y Deberes del Hombre. Con esa convicción y afán de protección, y

\footnotetext{
29 SAlmon (2010), p. 102. Mismo sentido Nash (2012 b), pp. 13-15.

30 Pérez Luño (2010), pp. 67-85.

31 SAlmon (2010), p. 101.

32 CANÇADO (2006), p. 337.
} 
debido a los eventos políticos de la época, en 1959 se estableció un comité de expertos que se denominó Comisión Interamericana de Derechos Humanos (en adelante CIDH, Comisión) cuyo objetivo era supervisar los derechos contenidos en la citada Declaración Americana. Esta Comisión, atendida en esa época la existencia de regímenes antidemocráticos y a la violación masiva y sistemática de derechos y libertades en el continente, desarrolló actividades, que si bien no estaban expresamente consagradas, las entendió como el ejercicio de facultades implícitas necesarias para cumplir mejor sus funciones. Esto le permitió indagar presuntas violaciones a los derechos humanos en los diferentes países. Por la inactividad de los Estados -estos no objetaron dichos procedimientos-aceptando naturalmente, en forma tácita, su validez ${ }^{33}$. En este avance desde 1948, la consolidación se concretó con la adopción de la Convención Americana sobre Derechos Humanos. Los esfuerzos por la adopción de un tratado vienen desde 1959 por los eventos de la República Dominicana y Cuba, ${ }^{34}$ donde hubo violación masiva de los derechos humanos por parte de los Estados, entre ellas ejecuciones, desapariciones, como muestra la literatura de acceso público. La Convención se abrió a firmas el 22 de noviembre de 1969 y entró finalmente en vigor el 18 de julio de 1978. Esta Convención creó una Corte Interamericana de Derechos Humanos y le otorgó facultades adicionales a la $\mathrm{CIDH}^{35}$.

La profundización en materia de pactos ha seguido su curso en los años posteriores, pues el sistema interamericano ha adoptado otros tratados. En el caso de la Convención Americana ella ha sido expandida a través de protocolos. Así el Protocolo Adicional en materia de Derechos Económicos, Sociales y Culturales (1999). Asimismo, en el contexto interamericano se han acordado varios tratados sobre derechos humanos de diferente naturaleza, entre ellos la Convención Interamericana para Prevenir y Sancionar la Tortura (en adelante C. Tortura) de 1987 y la Convención Interamericana sobre desaparición forzada de personas, vigentes actualmente y siendo la más antigua la C. Tortura. De la misma forma, son estos propios tratados que si bien no tienen el estatus formal de protocolos a la Convención, hacen parte integral del sistema interamericano, dentro de lo que la Corte ha denominado Corpus Iuris ${ }^{36}$. Estos mismos tratados, además, le

\footnotetext{
33 SÁNCHEZ (2010), pp. 12-15.

34 Ibídem, p. 15.

35 Ibídem, p. 15.

36 Ibídem, pp. 17-19.
} 
otorgan competencia material a la CIDH y a la Corte IDH en diferentes materias como por ejemplo conocer casos individuales, según lo estipulado en el artículo $8^{\circ}$ de la C. Tortura. Por otro lado, durante la primera semana de junio de 2013, en Guatemala y en el marco de la Asamblea General anual, aprobaron dos nuevos tratados internacionales a favor de la igualdad y la no discriminación: la Convención Interamericana contra el Racismo, la Discriminación Racial y Formas Conexas de Intolerancia y la Convención Interamericana contra Toda Forma de Discriminación e Intolerancia ${ }^{37}$.

Esa evolución, la podemos resumir en palabras del Diputado de la Asamblea Constituyente Isaac Adolphe Crémieux: "en la época en que vivimos, la proclamación de derechos de 1791(se refiere a la 1789, ratificada al aprobarse el texto íntegro de la Constitución de 1791), ya no es suficiente. Porque fue hecha en un tiempo en el que las ideas políticas y sociales no estaban suficientemente aclaradas". Y continuaba: "sin duda los que vengan después de nosotros lo harán mejor que lo que nosotros lo hacemos. La perfectibilidad del hombre está en nuestra naturaleza. Dentro de cincuenta años se harán adquisiciones a las que nosotros no hemos llegado. Pero nosotros hemos tenido hallazgos que no se tuvieron hace cincuenta años"38.

En esa perspectiva la Corte IDH, desde los primeros años de funcionamiento en su interpretación de la Convención, ha recalcado el talante sui géneris de los tratados de derechos humanos y la aplicación de la doctrina del effet utile. Además la Corte ha buscado una hermenéutica evolutiva de los tratados, usando interpretaciones contemporáneas de las disposiciones de la Convención Americana ${ }^{39}$. Ahora bien, la naturaleza de los tratados de derechos humanos, en el marco del Derecho Internacional de los Derechos Humanos (en adelante DIDH) presentan características especiales, en efecto la Corte IDH ha expresado en su Opinión consultiva OC-2/82 de 24 de septiembre de 1982 que “...los tratados modernos sobre derechos humanos, en general, y en particular, la Convención Americana, no son tratados multilaterales del tipo tradicional, concluidos en función de un intercambio recíproco de derechos, para el beneficio mutuo de los Estados contratantes. Su objeto y fin son la protección de los derechos fundamentales de los seres humanos, independientemente de su nacionalidad, tanto frente a su propio

\footnotetext{
37 Gauché (2014), p. 28.

38 GonZÁLEZ (2002), p, 17.

39 SÁNCHEZ (2010), p. 37.
} 
Estado como frente a los otros Estados contratantes. $\mathrm{Al}$ aprobar estos tratados sobre derechos humanos, los Estados se someten a un orden legal dentro del cual ellos, por el bien común, asumen varias obligaciones, no en relación con otros Estados, sino hacia los individuos bajo su jurisdicción" ${ }^{2}$. En la trayectoria de este trabajo, la Opinión Consultiva citada, en cuanto manifiesta que los tratados de derechos humanos tienen por objeto y fin la protección de los derechos fundamentales de los seres humanos, marcó un hito respecto al trabajo que desarrollaría la Corte IDH en la protección de los derechos humanos. Allí definió su trabajo con notable claridad. Por ello -en relación a este ensayo- cabe preguntarse de inmediato si este paso (con toda la historia que sucintamente hemos descrito), de esbozar un control de convencionalidad en sus primeras etapas, que además debe practicar en un origen el Poder Judicial de los Estados nacionales (adherentes a la CADH) ¿es derechamente un acto racional o irracional? Irracional, en cuanto acto arbitrario, fuera de todo límite aceptable. En una primera aproximación -por lo que ha significado la lucha de los derechos humanos, según lo descrito- se desprende una tendencia a que esa noción y ejercicio denominado control de convencionalidad en sus primeras etapas de desarrollo, sigue la ruta de la racionalidad. En especial, si se tiene en cuenta que un organismo cuasijudicial, como es la $\mathrm{CIDH}$, pudo realizar múltiples tareas (aceptadas por los Estados) -aun teniendo pocas facultades- para la defensa de los derechos humanos; luego, aparece muy racional que la Corte IDH en su calidad de órgano jurisdiccional y dentro de sus facultades, pueda diseñar el control de convencionalidad.

\section{SÍNTESIS}

La Segunda Guerra Mundial y varios hechos sociales y políticos de trascendencia ocurridos en Latinoamérica, hicieron despertar de una manera robusta a la comunidad jurídica internacional, sobre la necesidad imperiosa de proteger los derechos humanos. Esta materia fue regulada jurídicamente primero en declaraciones, luego en convenciones, por los Estados. En el caso interamericano, dos instituciones relevantes (entre muchas otras) han venido realizando esa labor de protección; la Comisión Interamericana de Derechos Humanos y la Corte Interamericana de Derecho Humanos. Trabajo de protección de dichos derechos que se enmarca en la racionalidad (crítica, fundamentación) de protección de los derechos humanos.

40 SALMON (2010), p. 103. 


\section{CONCRETA EVOLUCión JURISPRUdENCIAL DEL CONTROL DE CONVENCIONALIDAD}

\section{III.1. Primeras etapas}

Sobre esta materia, existe un consenso preciso en doctrina en cuanto al desarrollo en virtud del cual se fue formando dicha institución ${ }^{41}$. Un cuadro ilustrativo de las primeras etapas realizadas -que es en lo que se inscribe este artículo-, lo describe Claudio Nash (sin perjuicio de lo que se explicará a continuación) quien distingue cuatro etapas ${ }^{42}$. En efecto, podemos decir que es en la primera, donde se construyen los principales aspectos; esencialmente que es el Poder Judicial quien debe cumplir con la normativa internacional; siendo este un ejercicio hermenéutico. La segunda, es que el control de convencionalidad debe ejercerse incluso de oficio por la magistratura local. Dentro del ámbito de las competencias y funciones de la magistratura. La tercera, apunta a que este control compete a cualquier juez o tribunal que materialmente realice funciones jurisdiccionales. La cuarta, la Corte IDH incorpora como órgano competente para realizar dicho control a toda autoridad pública. En otra perspectiva de la evolución y tal como lo expone Carbonell, 43 es posible realizar un resumen de los sujetos obligados a examinar la convencionalidad de actos y normas. Se observa que la jurisprudencia de la Corte IDH ha atravesado cuatro fases, como son: a) el sujeto que lleva a cabo ese control de convencionalidad es el Poder Judicial (caso Almonacid Arellano) ; b) la Corte IDH señaló a "Órganos del Poder Judicial" (caso Trabajadores cesados del Congreso); c) se habla de "Jueces y Órganos vinculados a la administración de Justicia en todos sus niveles "(caso Cabrera García y Montiel Flores); d) finalmente, en estas etapas iniciales, se establece que el control de convencionalidad recae en cualquier autoridad pública y no solamente en el Poder Judicial (caso Gelman contra Uruguay).

\footnotetext{
41 Entre muchos autores, podemos indicar a: NASH (2012 a), pp. 58-64; NASH (2012 b), pp. 51-60; Nogueira (2014), pp. 395-406; Verbic (2012), pp. 2- 6; Corte Interamericana de Derechos Humanos (2016), pp. 1-10.

42 NASH (2012 b), pp. 57-59.

43 Carbonell (S/A), p. 75.
} 


\section{III.2. Etapa previa}

Un aspecto a considerar en su origen, son las dificultades que se encuentran en América Latina para dotar de efectividad al Pacto ${ }^{44}$. Ahora bien, la primera mención del término "control de convencionalidad" aparece en la jurisprudencia de la Corte por intermedio de un voto del Juez García Ramírez al dictarse sentencia en el caso Myrna Mack Chang vs. Guatemala ${ }^{45}$. Señala Hitters, que este tipo de control fue ejercido desde siempre por dicho tribunal ${ }^{46}$. Debemos agregar, como expone Aguilar, que el control cv se ha venido ejerciendo en Europa por otros tribunales, por lo menos desde $1975^{47}$. Luego de dicho caso, el Juez García Ramírez volvió a referirse al tema en dos ocasiones más, antes de que la Corte en pleno asumiera el concepto como propio con esa precisa terminología. La primera de ellas fue el caso "Tibi" donde el magistrado comparó la tarea de los tribunales internacionales con la que desarrollan los jueces locales en materia de control de constitucionalidad ${ }^{48}$. La segunda fue a comienzos del año 2006 en la causa "López Álvarez", donde el tribunal analizaba una posible vulneración del derecho a ser juzgado en un plazo razonable. En esta última ocasión, García Ramírez afirmó que el control de convencionalidad involucra tanto el análisis de cuestiones de hecho como de derecho ${ }^{49}$.

\section{III.3. Etapa de pronunciamiento del Pleno de la Corte IDH}

La Corte IDH se pronunció sobre el tema por primera vez en pleno al dictar sentencia en el caso "Almonacid Arellano" (2006). Allí el tribunal estableció que la ejecución extrajudicial de Almonacid Arellano, cometida por agentes estatales, constituía un crimen de lesa humanidad y sostuvo que los Estados no pueden sustraerse del deber de investigar, determinar y sancionar a los responsables de tales crímenes mediante la aplicación de leyes de amnistía u otro tipo de normativa interna. En esta oportunidad el tribunal (párrafo 124 de la sentencia aludida)

\footnotetext{
44 VerBiC (2016), p. 3.

45 Carbonell (S/A), pp. 71-72.

46 Verbic (2012), p. 6.

47 Aguilar (2013), p. 728. El publicista, en un excelente estudio de derecho comparado, blasona que la Corte de Casación francesa realizó un control de convencionalidad en el caso Société des Cafés Jacques Vabre.

48 Carbonell (s/a), pp. 72-73.

49 VERBIC (2012), p. 6.
} 
afirmó que aun cuando los jueces deben en principio aplicar las normas vigentes en el ordenamiento jurídico del país donde ejercen sus funciones, desde el momento en que tal país ratifica una Convención Internacional como el Pacto, esos jueces pasan a estar obligados también por dicha Convención Internacional. Y es por eso que deben ejercer "una especie de 'control de convencionalidad' entre las normas jurídicas internas (...) y la Convención”. Más importante aún, en esta sentencia el tribunal afirmó que, a la hora de ejercer el control de convencionalidad que deriva de dicha obligación, los jueces locales deben efectuar la comparación teniendo en cuenta no sólo la letra del Pacto o Tratado de que se trate sino también la interpretación efectuada por la propia Corte en torno a sus previsiones. La incorporación de este control de convencionalidad en la jurisprudencia de la Corte encuentra su fundamento en la búsqueda por lograr que los tribunales de justicia de los Estados Parte del sistema interamericano se sintieran involucrados y obligados a observar y cumplir lo establecido por el Pacto. Tribunales, que configuran "uno de los componentes del Estado que más difíciles son de abrir ante la realidad que muestra el derecho de origen internacional" 50 (Primera Etapa).

Por otro lado, tan sólo dos meses después, la cuestión fue abordada nuevamente por todos los miembros de la Corte al expedirse en el caso "Trabajadores Cesados del Congreso"(2006)51. En esta oportunidad el tribunal repitió el holding de "Almonacid Arellano" y además dejó en claro que no es necesaria una petición de parte para llevar adelante el control. En tal sentido sostuvo que "los órganos del Poder Judicial deben ejercer no sólo un control de constitucionalidad, sino también "de convencionalidad "ex officio» entre las normas internas y la Convención Americana"52. Aquí, a diferencia del caso Almonacid, hay un mayor nivel de "determinación jurídica en torno a la naturaleza del control de convencionalidad" 53 . Esta decisión es relevante, pues indica el carácter oficioso con que los jueces deben llevar a cabo el control de convencionalidad. Incluso, no importando la naturaleza del litigio, ya sea este público o privado. Ello debido a la eficacia de los tratados internacionales y el pleno cumplimiento de las obligaciones que en ellos se consagran. Sin duda que todo lo anterior justifica que los

\footnotetext{
50 Ibídem (2012), pp. 7-8.

51 Carbonell (S/A), pp. 73-74.

52 Verbic (2012), p. 8.

53 Ibídem, p. 8.
} 
jueces siempre tengan presentes las disposiciones convencionales al resolver los litigios objeto de su conocimiento ${ }^{54}$. (Segunda Etapa).

Transcurrido un año desde el fallo en el caso "Almonacid Arellano y otros versus Chile", la Corte IDH, reflexionó nuevamente el asunto en la causa "Boyce versus Barbados" (2007). Se trataba de un caso en el cual una sentencia había dispuesto la pena de muerte de dos personas y los tribunales nacionales se negaron a revisarla con fundamento en una norma de derecho interno que les impedía proceder en tal sentido ${ }^{55}$. En esta fase, la Corte Interamericana señaló que la Corte de Justicia del Caribe (máximo órgano jurisdiccional en sede local) había efectuado un análisis puramente constitucional del asunto, omitiendo tomar en consideración las obligaciones internacionales asumidas por Barbados al suscribir el Pacto. En términos simples, explica que los tribunales nacionales no solo deben limitarse a realizar un examen de constitucionalidad de sus resoluciones, sino también de convencionalidad $^{56}$. (Tercera Etapa).

Avanzando en diseñar el concepto del control de convencionalidad en estas etapas iniciales, en el caso "Heliodoro Portugal versus Panamá" (2008) la Corte sumó otro postulado para delinear los alcances de este control cv. Allí sostuvo que por intermedio de este control cada juez local debe velar por el "efecto útil" del Pacto y demás convenciones. Efecto útil que depende, según afirmó el propio tribunal, de la adecuación del derecho doméstico a las exigencias contenidas en los instrumentos internacionales ${ }^{57}$. (Cuarta Etapa).

Como es posible observar, siguiendo nuestra hipótesis de trabajo, en esa decisión decantada y reflexiva que fue haciendo la Corte IDH de la Convención, nace otro elemento que integra dicho control. Expresó ese Tribunal que este control le compete a cualquier juez o tribunal que materialmente realice funciones jurisdiccionales y que se efectúe en el ámbito de la competencia de cada magistratura, "Cabrera García y Montiel versus México" (2010). Con esta jurisprudencia se produce una apertura hacia los Tribunales Constitucionales. Esto es, se reafirma la idea de que todo juez debe realizar ese control con independencia de las características particulares de la organización de sus funciones. Asimismo, en este

\footnotetext{
54 Carbonell (S/A), pp. 73-74.

55 VERBIC (2012), pp. 9-10.

56 Corte Interamericana de Derechos Humanos (2016), p. 5.

57 Verbic (2012), p. 10.
} 
fallo se aclara cualquier duda sobre la naturaleza de la institución y los alcances interpretativos del control de convencionalidad ${ }^{58}$. (Quinta Etapa).

La Corte IDH además especificando este control de convencionalidad, incorpora como órgano competente para realizar dicho control a toda autoridad pública. Se amplía el abanico desde el Poder Judicial a todos los órganos públicos. Lo señaló en el caso "Gelman vs. Uruguay" (2011) a propósito del análisis de compatibilidad de una ley de amnistía aprobada democráticamente con las obligaciones que impone la $\mathrm{CADH}^{59}$. (Sexta Etapa).

Otro rasgo del avance de la Jurisprudencia con relación al control de convencionalidad en estas primeras etapas, es que el parámetro de convencionalidad fue ampliado a las opiniones consultivas, tal como se señaló en esta materia en el caso de la migración de niñas, niños y adolescentes, el año 2014. Esto implica que los órganos del Estado realicen el correspondiente control de convencionalidad, también sobre la base de lo que señale en ejercicio de su competencia no contenciosa o consultiva ${ }^{60}$. (Séptima Etapa).

Manteniendo la cavilación precedente, hay que resaltar que la Corte IDH, a partir del caso Almonacid Arellano y otros vs. Chile, fallado el 26 de septiembre de 2006, ha incluido, en estas iniciales etapas de desarrollo, aproximadamente en 29 de sus fallos, el concepto control de convencionalidad. Además de la indicada sentencia, se inicia con el caso la Cantuta vs. Perú de 29 noviembre de 2006, hasta caso Rochac Hernández y otros vs. El Salvador de 14 de octubre de 201461. En el análisis de estas etapas aludidas que es el objeto de este artículo, es posible distinguir al menos, como apunta $\mathrm{Nash}^{62}$, las siguientes características del control de convencionalidad: a) debe ser practicada de oficio por toda autoridad pública; b) su ejercicio se realiza en el ámbito de competencia de cada autoridad; c) la obligación que está siempre presente es la de realizar un ejercicio hermenéutico, que haga compatible las obligaciones del Estado con sus normas internas; d) es baremo de convencionalidad, la Jurisprudencia de la Corte IDH, agregamos nosotros, de la competencia contenciosa y también no contenciosa o consultiva; e) la obligación de realizar el control deriva de las obligaciones internacionales

\footnotetext{
58 NASH (2012 b), p. 58-59.

59 Ibídem, pp. 59-60.

60 Corte Interamericana de Derechos Humanos (2016), pp. 11- 12.

61 VIO (2015), pp. 94-95.

62 Nash (2012 b), pp. 59-60.
} 
del Estado. Finalmente en este capítulo, podemos discernir que la Corte IDH, en estas iniciales etapas de determinación del control cv, ha tenido una decisión de amparo al ir ampliando el número de sujetos que deben realizar el control de convencionalidad. Como expresa Carbonell, es dar aplicación en forma congruente y holística al principio pro persona. Reiterando además el deber de los Estados de cumplir con lo que prescriben los tratados internacionales. No siendo óbice lo estatuido por el derecho interno. ${ }^{63}$

\section{SÍNTESIS}

La creación jurisprudencial del control de convencionalidad tiene una formación pausada y reflexiva en estas etapas iniciales. Primero cavila un solo juez en un voto razonado, varias veces, para luego -años de después- tomar el pleno de la Corte IDH la doctrina del control cv. Esta institución del control de convencionalidad se ha ido enriqueciendo y precisando con nuevos aportes que ha realizado la Corte para su mayor comprensión.

\section{NOCIÓN DEL CONTROL DE CONVENCIONALIDAD}

En una revisión del panorama de definiciones sobre el control de convencionalidad, en general la doctrina, sin mayor debate, entiende de manera uniforme de inicio que es un ejercicio jurisdiccional y lo nombra de diferentes formas. Así: comunicación interjurisdiccional, control, comparación, examen, obligación de los órganos del Estado. Ejercicio que se realiza entre las normas domésticas y las disposiciones de la Convención Americana sobre Derechos Humanos y la Jurisprudencia desarrollada por la Corte IDH sobre la materia. Con el objeto de que exista una integración armónica entre los derechos en juego. Ello sin perjuicio -como se observó ut supra- de nuevos contenidos que la Jurisprudencia de la Corte Interamericana seguirá incorporando ${ }^{64}$. Antes de esbozar un mejor concepto, es importante realizar una distinción entre lo que es el control de constitucionalidad y el control de convencionalidad. Hitters ${ }^{65}$ explica que el control

63 Carbonell (S/A), p. 75.

64 Diferentes autores se manifiestan en este sentido: Verbic (2012), p. 5; Hitters (2009), p. 109; Aguilar (2013), p. 721; Nogueira (2013), pp. 79; Corte Interamericana de Derechos Humanos (2016), pp. 6-7; NASH (2012 b), p. 52.

65 Hitters (2009), p. 110. 
de constitucionalidad se ejerce por órganos jurisdiccionales locales e implica una comparación entre la carta constitucional del país donde dichos órganos ejercen su labor y las normas de rango inferior allí vigentes. Este cotejo debiera terminar en un pronunciamiento donde se otorgue primacía a la primera sobre las segundas. (Cuyo origen sabemos se encuentra en el precedente "Marbury vs. Madison", dictado por la Corte Suprema de Estados Unidos de Norteamérica en 1803). En cambio, control de convencionalidad, es un concepto mucho más reciente como derivación del proceso de internacionalización del derecho constitucional, luego de finalizada la Segunda Guerra Mundial ${ }^{66}$. Ahora bien, a diferencia del instrumento anterior, el control de convencionalidad significa una comparación entre el Pacto de San José de Costa Rica y otras convenciones internacionales, por un lado, y las disposiciones de derecho interno de los países que conforman el sistema interamericano, por el otro (normas legislativas, administrativas y de cualquier otro tipo $)^{67}$. Es decir el primero se desarrolla en el ámbito local interno entre el derecho interno y la Constitución. El segundo es más amplio a nivel de comparación de normas, puesto que se realiza entre las normas del derecho doméstico, la $\mathrm{CADH}$, otros pactos y la Jurisprudencia de la Corte IDH. Entrando de lleno a la noción, podemos indicar que el control de convencionalidad es la herramienta que permite a los Estados concretar la obligación de garantía de los derechos humanos en el ámbito interno, a través de la verificación de la conformidad con la Convención Americana de Derechos Humanos y su jurisprudencia, de las normas y prácticas nacionales ${ }^{68}$. Lo trascendente es que se concreta la obligación de garantía, que se traduce en la obligación que asume el Estado de promover, a través de sus órganos, la posibilidad real y efectiva de que sus ciudadanos ejerzan los derechos y disfruten las libertades. Por ello, el control de convencionalidad hay que observarlo desde dos aristas. En sede internacional que implica una subordinación de todo el ordenamiento jurídico, al respeto y garantía de los derechos humanos asegurados convencionalmente, lo que tiene como fundamento que los derechos esenciales de la persona son parte del bien común general regional, que es superior al bien común nacional. Por lo que desde el punto vista jurídico, se debe preferir los estándares mínimos de los derechos asegurados por la Convención a niveles inferiores de aseguramiento de garantías y derechos asegurado por el

66 Verbic (2012), pp. 3-4.

67 Hitters (2009), p. 110.

68 NASH (2012 b), p. 52. 
derecho interno, incluida la Constitución. En sede interna es donde se concreta por los órganos, autoridades y funcionarios del Estado Parte, en la medida que el corpus iuris interamericano es parte del derecho nacional. Corpus iuris que tiene prevalencia sobre el derecho interno, cuando este último se encuentre por debajo del estándar mínimo asegurado convencionalmente ${ }^{69}$.

Finalmente, un resumen de lo anterior en estas iniciales etapas, según el objetivo de este trabajo, lo precisa la Corte IDH indicando que el control cv consiste en: a) verificar la compatibilidad de las normas y demás prácticas internas con la $\mathrm{CADH}$, la jurisprudencia de la Corte IDH y los demás tratados interamericanos de los cuales el Estado sea Parte; b) es una obligación que corresponde a toda autoridad pública en el ámbito de sus competencias; c) es un control que debe ser realizado ex officio por toda autoridad pública; $y$ d) su ejecución puede implicar la supresión de normas contrarias a la $\mathrm{CADH}$ o bien su interpretación conforme a la $\mathrm{CADH}$, dependiendo de las facultades de cada autoridad pública (la Convención Americana sobre derechos humanos no impone un determinado modelo de control de convencionalidad $)^{70}$.

\section{SÍNTESIS}

La noción de control de convencionalidad, en estas primeras etapas, también tiene un surgimiento decantado, que puede ir de una simple alusión a un cotejo de normas (lo que se busca es un cotejo de las normas internacionales con el derecho interno), para llegar a distinguir luego sus fases externa e interna y las características que a través de un trabajo reflexivo y fundamentado le ha dado la Corte IDH.

\section{DETECCIÓN DE LAS CRÍTICAS MÁS RELEVANTES REALIZADAS AL CONTROL DE CONVENCIONALIDAD EN ESTAS PRIMERAS ETAPAS}

\section{V.1. Aproximación}

Tanto los publicistas como los propios jueces han recogido, realizado distintas y variadas observaciones, además de reproches, a la institución denominada "control

69 Nogueira (2014), p. 399.

70 Corte Interamericana de Derechos Humanos (2016), pp. 6-12. 
de convencionalidad"71. Ahora bien, luego de revisar la literatura sobre el tema, podemos agrupar dichas observaciones y alcances, en dos grandes vertientes. La primera tiene que ver con la mirada externa (con relación al Estado nacional); esto es, el derecho internacional, la Corte IDH y su jurisprudencia. La segunda, se dirige a lo interno (con relación al Estado nacional); es decir que ha significado, o bien que ha provocado la aplicación del control de convencionalidad en cada país miembro de la $\mathrm{CADH}$. En ambos caminos, las alegaciones las hemos resumido en siete críticas. Externo: a) ¿cuál es la legitimidad de los Tribunales Internacionales?; b) ¿qué es el control de convencionalidad?; c) ¿qué fundamentos normativos y su carácter vinculante tiene el Pacto, para el control de convencionalidad?; d) ¿qué

${ }^{71}$ Los diferentes reparos son: a) Legitimidad de los jueces para inaplicar y expulsar normas, NASH (2012 b), p. 60; b) Control de convencionalidad y la obligación de cumplir con las sentencias, NASH (2012 b), p. 61; NASH (2014), pp. 457-458; IvansChitz (2014), p. 425, pp. 429-430; CARbONell (S/A), pp. 69-71; c) Límite entre la obligación de los jueces para implementar dicho control y evitar que el Estado incurra en responsabilidad internacional y la obligación del Poder legislativo de superar antinomias graves entre la legislación interna y los compromisos internacionales del Estado, NASH (2012 b), p. 61; d) Disyuntiva entre monismo y dualismo, ESPINOSA-SALDAÑA (2015), p. 88; e) ¿Control de convencionalidad y aplicación de la Convención es lo mismo? Ibídem (2015), p. 89; f) Sentencias de Imposible cumplimiento. Ibídem (2015), p. 90; g) Amenaza a la soberanía estatal. Ibídem (2015), p. 90; h) ¿ Que vamos a entender por ese Control de Convencionalidad?, Ibídem (2015), p. 91; Collí ( 2015), pp. 157-160; Nogueira (2014), pp. 398-406; i) Preocupación por el camino que estaría tomando la Jurisprudencia de la Corte IDH sobre concepto del control de convencionalidad, VIO (2015), pp. 96-103; j) ¿Es lo mismo control de convencionalidad y control de constitucionalidad?, Vio (2015), p. 108; GARCía (2014), pp. 355-356; HitTers (2009), pp. 110-111; VerBIC (2012) p. 2-3; k) Alteración del sistema jurídico del Estado Parte por aplicación del control CV. RoJas (2015), p. 115; l) afectación por el control de convencionalidad del principio de subsidiariedad y su margen de apreciación. Ibídem (2015), p. 116; MarTínez (2014), pp. 335-340; GarCía (2014), pp. 360-367; m) ¿Que cobija el control de convencionalidad, normas jurídicas y no conductas?, RoJAS (2015), pp. 119-127; n) Control de Convencionalidad y el ámbito de las competencias. Ibídem (2015), pp. 129-130; SAGÜES

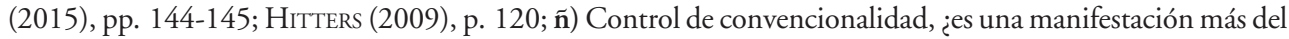
gobierno de los jueces? KeSSAL-Wulf (2015), pp. 176-177; o) Control de Convencionalidad y la aplicación del mejor derecho. SAGÜES (2014), pp. 15-16; p) Fundamentos normativos del Pacto, para el control de convencionalidad. Ibídem (2014), pp. 16-17; Nogueira (2014), pp. 395-398; q) ¿Qué es la aplicación interna del control de convencionalidad? SAGÜES (2014), pp. 19-21; RIVERA (2014), p. 57; Nogueira (2014), pp. 406-419; NúNEZ (2014), pp. 175-177; r) Control de convencionalidad y su carácter vinculante, EsPINOSASaldaÑa (2014), pp. 144-146; Carbonell (S/A), pp. 69-71); s) Legitimidad de los tribunales internacionales, Muñoz (2014), p. 150; Carbonell (S/A) pp. 69-71; t) Control de Convencionalidad, debe ser concreto o abstracto, HitTers (2009), pp. 118-119; VerbiC (2012) pp. 2-5 ; u) normas supranacionales, sobre las que se debe ejercer el control de convencionalidad, HitTers (2009), p. 120; v) normas nacionales, sobre las que se debe ejercer la comparación, Ibídem (2009), p. 120; w) consecuencias que derivan del control de convencionalidad realizado por la Corte IDH. Ibídem (2009), pp. 122-123; x) Grado de receptividad en los Estados para el control CV. Verbic (2012) pp. 11-14; y) ¿Pueden los tribunales inaplicar una ley fundado en un supuesto control de convencionalidad o en decisiones de pautas hermenéuticas o decisiones judiciales de la Corte?, IŃIguez (2014), p. 383. 
consecuencias derivan del control de convencionalidad realizado por la Corte IDH?; e) dicho control ¿es una amenaza a la soberanía estatal? ; f) ¿̇se tornan las sentencias de la Corte IDH de imposible cumplimiento, al aplicar el control de convencionalidad?; g) ¿es el control de convencionalidad, una manifestación más del gobierno de los jueces?

Lo interno: a)¿ qué vamos a entender por ese control de convencionalidad?; b) ¿̇sobre qué normas se debe ejercer el control de convencionalidad?; c) ¿ cuál es la legitimidad de los jueces para inaplicar o expulsar normas?; d) ¿ obliga el control de convencionalidad a cumplir con las sentencias?; e) ¿cuáles son los límites entre la obligación de los jueces para implementar dicho control y evitar que el Estado incurra en responsabilidad internacional y la obligación del poder legislativo de superar antinomias graves entre la legislación interna y los compromisos internacionales del Estado?; f) ¿cuál es la Jurisprudencia de la Corte IDH aplicable?; g) ¿cuál es el grado de receptividad en los Estados para aplicar el control de convencionalidad?

Como puede avizorarse -y sin perjuicio de lo que se expresará en el apartado siguiente- los reparos, si bien algunos más fundados que otros, expresan un desconocimiento y olvidan, según se analizó ut supra, todo el avance que el derecho internacional de los derechos humanos ha venido realizando en los últimos 75 años. Avance, que está suficientemente documentado y de acceso libre. En cuanto a la legitimidad de los tribunales, son los propios Estados quienes voluntariamente han adherido a las respectivas Convenciones (¿cómo voy a alegar ilegitimidad a un acto que yo he ayudado a crear?). Asimismo, no es atendible que no se entiendan determinados conceptos, como el propio control de convencionalidad, en circunstancias que los tribunales nacionales al decidir causas, desde hace más de cien años vienen resolviendo temas de igual o mayor complejidad; como son los recursos extraordinarios. Así, las casaciones, las nulidades o bien las revisiones, ello sin perjuicio de temas más difíciles que deben resolver conociendo los recursos ordinarios como las apelaciones, o bien todo tipo de acciones de amparo constitucional ${ }^{72}$. Las críticas, por otro lado, no han considerado un elemento esencial, que es crear conciencia jurídica internacional para la defensa de los derechos humanos en to-

72 Revista de Derecho y Jurisprudencia, (1991) p. 56 y p. 106. Los Tribunales chilenos, una vez que entró en vigencia la CADH -fue publicada en el Diario Oficial el 5 de enero de 1991-, no tuvieron mayores problemas de ejercer un control de convencionalidad, como se aprecia en el conocimiento de recursos de amparo (habeas corpus), revisados por las Cortes de Apelaciones, al conocer las denegatorias de libertad de presos en causas por giro doloso de cheques. 
dos los Estados y tener por obligación principal la protección integral de dichos derechos. Si se examina con este enfoque los reproches al control cv, ninguna de ellos pasa el tamiz de los razonamientos anteriores, ni los elementos básicos que con posterioridad se señalarán. Ahora bien, cabe la siguiente reflexión, ¿por qué un Tribunal, un órgano u otra autoridad debiera elegir esas razones (todos los reparos que hemos enumerado) y no el ejercicio del control de convencionalidad, para la mejor protección de los derechos fundamentales? Racionalmente, no hay razones para omitir el control cv (salvo que exista un estándar de protección mayor). Si efectivamente se desecha realizar dicho control, sería por argumentos no racionales, como se explicará al final de este artículo.

\section{V.2. Elementos básicos que debe superar toda critica al control de convencionalidad}

Para resolver lo planteado en la introducción de este trabajo en estas iniciales etapas de construcción del control cv, como las interrogantes descritas anteriormente, sobre la misma institución, desde el enfoque de la razón, como se expresó además en el título, es imprescindible tener en consideración los siguientes elementos mínimos que toda crítica para ser tal debe derribar:

a) Fundamento normativo del control cv. Como explica Nash ${ }^{73}$, en lo central encontramos (ello sin perjuicio de principios del Derecho Internacional), en el ámbito interno los artículos $1^{\circ}, 5^{\circ}$ y $6^{\circ}$ de la Constitución Política, en cuanto el artículo $1^{\circ}$ se refiere a que las personas nacen libres e iguales en dignidad y derechos; el artículo $5^{\circ}$ respecto a que la soberanía reconoce como límite los derechos esenciales que emanan de la naturaleza humana debiendo los órganos estatales respetar y promover los derechos fundamentales consagrados en la Constitución y en los tratados internacionales ratificados por Chile que se encuentran vigentes; $y$ artículo $6^{\circ}$ en relación a que los órganos del Estado deben someter su acción a la Constitución y a las normas dictadas conforme a ella. La normativa internacional se apoya en la lectura conjunta de los artículos 1.1, $2^{\circ}$ y 29 de la $\mathrm{CADH}^{74}$. En efecto, de su lectura se desprende que la protección de los derechos humanos debe ser guía en la actuación de los Estados. Estos deben tomar todas las medidas para asegurar el respeto y promoción de dichos derechos. Por ello, el concepto control

73 NASH (2012 b), pp. 54-56.

74 Convención Americana sobre Derechos Humanos (1969). Artículos 1º, 2o y 29. 
de convencionalidad se ha entendido como la obligación que tienen los jueces de efectuar no sólo un control de legalidad y de constitucionalidad en los asuntos de que conocen, sino de integrar en el sistema de sus decisiones las normas contenidas en la CADH y los estándares desarrollados por la jurisprudencia de la Corte IDH.

b) El sentido de los tratados de derechos humanos. Baste aquí recordar la Opinión consultiva OC-2/82 de 24 de septiembre de 1982, citada ut supra, que dispone "...los tratados modernos sobre derechos humanos, en general, y en particular, la Convención Americana, no son tratados multilaterales del tipo tradicional, concluidos en función de un intercambio recíproco de derechos, para el beneficio mutuo de los Estados contratantes. Su objeto y fin son la protección de los derechos fundamentales de los seres humanos, independientemente de su nacionalidad, tanto frente a su propio Estado como frente a los otros Estados contratantes. $\mathrm{Al}$ aprobar estos tratados sobre derechos humanos, los Estados se someten a un orden legal dentro del cual ellos, por el bien común, asumen varias obligaciones, no en relación con otros Estados, sino hacia los individuos bajo su jurisdicción”. Sobre esta materia, además, como lo expone Antônio A. Cançado Trindade ${ }^{75}$, en cuanto, estos tratados incorporan obligaciones de carácter objetivo que trascienden los meros compromisos recíprocos entre las partes. En suma, se vuelcan a la salvaguardia de los derechos del ser humano y no de los derechos de los Estados. Asimismo, toda la evolución jurisprudencial en lo referente a la interpretación propia de los tratados de protección internacional de los derechos humanos se encuentra orientada en ese sentido. Puntualiza el jurista, que estos tratados tienen una dimensión constitucional, no en el sentido de su posición en la jerarquía de normas en el derecho interno, sino en el sentido mucho más avanzado, de que construyen en el propio plano internacional un orden jurídico internacional de respeto a los derechos humanos ${ }^{76}$.

c) Obligaciones de los Estados al firmar un tratado de derechos humanos. Los Estados al adherir a la CADH, asumen varias obligaciones. Siguiendo al profesor Claudio Nash, podemos explicar que la obligación de cumplimiento en materia de derechos humanos, se materializa a través de tres obligaciones principales: respeto y garantía de los derechos y libertades consagradas internacionalmente, cualquiera sea el tipo de documento en el que se consagre y la obligación de no discriminar.

75 CANÇAdo (2006), p. 235.

76 CANÇADO (2012), p. 304. 
c.1) Obligación de respeto. Consiste en cumplir directamente con la conducta establecida en cada norma convencional, ya sea absteniéndose de actuar o dando una prestación. El contenido de la obligación estará definido, en consecuencia, a partir del mandato normativo del derecho o libertad concreto.

c. 2) Obligación de garantía. Se traduce en la obligación que asume el Estado de promover, a través de sus órganos, la posibilidad real y efectiva de que sus ciudadanos ejerzan los derechos y disfruten las libertades que se les reconocen. Es decir, el Estado está obligado a crear condiciones efectivas de goce y ejercicio de los derechos consagrados en la Convención. Es una obligación complementaria de respetar, no sólo el estricto cumplimiento del mandato normativo que establece cada derecho, sino una obligación positiva de crear las condiciones organizativas, institucionales y procedimentales para el pleno goce y ejercicio de los Derechos por las personas. Esta obligación implica siempre la adopción de medidas positivas. Cumple el Estado entre otras acciones: asegurando el pleno goce y ejercicio de los derechos.

c.3) Obligación de no discriminar. Es una obligación general el deber del Estado de no discriminar a las personas en el goce y ejercicio de sus derechos. Esta obligación ha sido destacada por la jurisprudencia internacional como un principio del Derecho Internacional de los Derechos Humanos e incluso, para la Corte IDH esta obligación sería una norma perentoria o de ius cogens ${ }^{77}$.

d) Interpretación. En materia de tratados de derechos humanos, como expresa Salmon ${ }^{78}$ para resolver un caso, como primer criterio de interpretación se utilizan las normas de la Convención sobre los tratados ${ }^{79}$. Su artículo 31 establece que un tratado deberá interpretarse de buena fe, conforme al sentido corriente que haya de atribuirse a los términos del tratado en el contexto de éstos y teniendo en cuenta su objeto y fin. En esa perspectiva también para construir la interpretación se han sistematizado ciertas directrices ${ }^{80}$ :

d.1) Pro persona. El objeto y fin del tratado es la protección de los derechos humanos. La interpretación siempre debe estar a favor del individuo (criterio, que es examinado con precisión en un apartado posterior).

\footnotetext{
77 NASH (2010), pp. 59-66.

78 Salmon (2010), pp. 104-106.

79 Convención de Viena sobre el Derecho de los Tratados y su anexo (1969). Artículo 31.

80 NASH (2012 b), pp. 32-33.
} 
d.2) Dinámica. El objeto y fin del tratado, como elemento interpretador, le confieren a éste un carácter dinámico. Un instrumento internacional debe ser interpretado y aplicado en el cuadro del conjunto del sistema jurídico en vigor, en el momento en que la interpretación tiene lugar. Los tratados son instrumentos vivos.

d.3) Integral. Las diversas fuentes del derecho internacional se influyen recíprocamente. Esto es, no es posible aplicar un tratado con desconocimiento de los principios generales de derecho o del derecho consuetudinario que lo precede o lo complementa, como tampoco es factible ignorar las otras fuentes del derecho que pueden haberlo sucedido, aclarándolo o complementándolo.

e) Irrelevancia de la alegación de dificultades de derecho interno. Como lo expone Cançado ${ }^{81}$, al ratificar los tratados de derechos humanos, los Estados partes contraen a la par de obligaciones específicas relativa a cada uno de los derechos protegidos, la obligación general de adecuar su ordenamiento jurídico interno a las normas internacionales de protección. Así las dos Convenciones de Viena sobre derechos de los tratados de 1969 y 1986, respectivamente, prohíben que una parte invoque disposiciones de su derecho interno para intentar justificar el descumplimiento de un tratado (artículo 27). Este es un precepto, más que de los derechos de los tratados, del derecho de la responsabilidad internacional del Estado, firmemente cristalizado en la jurisprudencia internacional. Lo cierto es que las supuestas dificultades de orden interno son un simple hecho y no eximen a los Estados Partes en tratados de derechos humanos de la responsabilidad internacional por el no-cumplimiento de las obligaciones internacionales contraídas. En ese sentido poco eco ha tenido para la Corte IDH la discreción nacional, a través del denominado margen de apreciación. Su empleo ha sido excepcional por la Corte IDH ${ }^{82}$.

f) Principio favor persona. Es un criterio hermenéutico que informa todo el derecho de los derechos humanos, en virtud del cual se debe acudir a la norma más amplia, o a la interpretación más extensiva, cuando se trata de reconocer derechos protegidos e inversamente, a la norma o a la interpretación más restringida cuando se trata de establecer restricciones permanentes al ejercicio de los derechos o su suspensión extraordinaria. Este principio coincide con el rasgo fundamental del derecho de los derechos humanos, esto es, estar siempre a favor

81 CANÇADO (2012), pp. 274-275.

82 Contreras (2014), pp. 250-265. 
del hombre"83. Resumiendo, este principio tiene dos dimensiones específicas: la primera como preferencia interpretativa y la segunda como preferencia normativa, independiente de su nivel jerárquico ${ }^{84}$. La Corte IDH ha aplicado ambas líneas, en reiterados fallos tanto como preferencia interpretativa y preferencia normativa. En esta preferencia, lo esencial es que aporta una solución práctica. El principio favor persona, como mandato de favorabilidad general, no considera que se deba atender a la jerarquía de las normas al resolver un caso concreto, siempre y cuando se esté dentro de las posibilidades jurídicas y fácticas del sistema jurídico respectivo, siendo dichas normas válidas y aplicables al caso. El principio favor persona exige la aplicación de la norma más favorable para la persona en el caso concreto, sin importar su naturaleza de derecho interno o internacional ${ }^{85}$.

g) Evolución del derecho. Afirma Cançado, que la corriente positivistavoluntarista, con su obsesión por la autonomía de la voluntad de los Estados, al buscar cristalizar las normas de éstas emanadas en un determinado momento histórico, llegó al extremo de concebir el derecho positivo independientemente del tiempo. De ahí su manifiesta incapacidad de acompañar los constantes cambios de las estructuras sociales, en los planos, tanto interno como internacional, por no haber previsto los nuevos supuestos de hecho para darles respuesta. Por ello su incapacidad de explicar la formación histórica de las reglas consuetudinarias del derecho internacional. Agrega, que la consolidación del Corpus Iuris del derecho internacional de los derechos humanos se debe a la reacción de la conciencia jurídica universal, ante los recurrentes abusos cometidos contra los seres humanos, frecuentemente convalidados por la ley positiva. Lo que sucedió a continuación, fue que el derecho vino al encuentro del ser humano, destinatario último de sus normas de protección. ${ }^{86}$

\section{SÍNTESIS}

Como se aprecia, todos los reparos y observaciones realizados al control de convencionalidad, desde la óptica de la racionalidad y el desarrollo DIDH no logran superar los requisitos mínimos antes invocados.

\footnotetext{
83 Nogueira (2015), p. 2.

84 Ibídem, p. 3.

85 Ibídem, pp. 9-11.

86 CANÇADO (2012), p. 115.
} 


\section{VI. ¿ES UN ACTO RACIONAL EL CONTROL DEL CONVENCIONALIDAD?}

Desarrollado los capítulos anteriores, en cuanto a la génesis histórica de la protección de los derechos humanos, la evolución jurisprudencial del control de convencionalidad y su noción en sus primeras etapas, más los elementos básicos antes aludidos, corresponde ahora realizar un examen de lo anteriormente descrito con el marco de racionalidad e irracionalidad explicado en el capítulo I. En esa perspectiva, esto lo podemos resumir de la siguiente manera:

a) Acción racional, en cuanto se utilizan los medios adecuados para lograr un fin deseado. A partir de la lectura de la $\mathrm{CADH}$, la Corte IDH, según lo precedentemente razonado, plantea un control $\mathrm{cv}$ apoyado en su normativa y en la interpretación evolutiva, dinámica e integral de la Convención aludida, para lograr la protección de los derechos humanos.

b) Acción racional, en cuanto permite argumentar, formar conceptos, criticar. De lo estudiado, es nítidamente observable que los magistrados de la Corte IDH, de manera reflexiva, primero a través de un voto disidente, comienzan a cavilar, a argumentar la labor que les corresponde a los jueces de los Estados nacionales para respetar y aplicar las normas de la $\mathrm{CADH}$ a través del ejercicio hermenéutico de este control cv.

c) Acción racional, en cuanto "algo es como es y no de otro modo". La adopción por parte del pleno de la Corte IDH del control cv, lo determina como algo específico que deben realizar los Estado nacionales, en una primera etapa a través de los jueces que integran el Poder Judicial. Es un ejercicio concreto, específico y no ambiguo, un examen y cotejo de normas, por lo que puede decirse que "algo es como es y no de otro modo".

d) Acción racional, en cuanto facultad de pensar y exigir lo incondicionado. Como lo hemos venido exponiendo, la racionalidad como parte de esta facultad de pensar. La Corte IDH, al asumir la noción de control cv, da las razones para exigir lo incondicionado, en cuanto si realmente, por un lado, la Corte IDH quiere que se respete la $\mathrm{CADH}$ y que los Estados cumplan con sus obligaciones, aparece nítido que sin duda deben hacer este ejercicio hermenéutico de control cv para el respeto, garantía y no discriminación de los derechos humanos en cada Estado nacional.

e) Acción racional, en cuanto el sujeto conoce el mundo por aquello que le está dado por el lenguaje. La Corte IDH se ha ceñido a un marco de reflexión y ponderación jurídica que ha mantenido desde su creación. El control cv viene a consolidar ese lenguaje jurídico que está en la $\mathrm{CADH}$, que se ha desarrollado por la Corte IDH a través de su jurisprudencia en múltiples fallos. 
f) Acción racional, en cuanto un sujeto hace una afirmación y es capaz de defenderla frente a un crítico, aduciendo las evidencias pertinentes. En ese caso, desde el fallo Amonacid Arellano y otros versus Chile, antes citado, la Corte IDH realiza un juicio y lo explica, siendo esto reproducible por cualquier observador $\mathrm{y}$ entendible además en conformidad a las normas de la CADH y su jurisprudencia que ha realizado a lo largo de los años.

g) Acción racional, en cuanto un sujeto sigue una norma vigente y es capaz de justificar su acción frente a un crítico, interpretando una situación dada a la luz de expectativas legítimas de comportamiento. Como se explicó precedentemente y también en los capítulos anteriores, hay fundamentos normativos precisos para ejercer el control cv. La Corte IDH y los Estados nacionales respectivos, lo han realizado concretando las expectativas legítimas de comportamiento que se espera al adherir a una convención sobre derechos humanos, principalmente por las obligaciones que hay que cumplir de respeto, garantía y no discriminación.

h) Acción racional, en cuanto un sujeto delibera hasta encontrar lo mejor que se le ofrece (racionalidad deliberativa). Como es posible observar, a través del desarrollo de este artículo, la Corte IDH desde sus orígenes y en sus primeras etapas, ha ido reflexionando lentamente hasta encontrar, respecto a la protección de los derechos humanos, lo mejor que puede ofrecer tanto la CADH y la interpretación de sus normas a través de su jurisprudencia consolidada. Hoy, a la luz de estas etapas iniciales, aparece que tanto la Corte IDH como los Estados nacionales respectivos, han deliberado y han encontrado la mejor solución posible para la aplicación efectiva de la $\mathrm{CADH}$ en la protección de los derechos humanos.

i) Acción racional, en cuanto se utiliza un marco de modelo procedimental (en este caso específico el procedimiento judicial). Finalmente, después de todo lo cavilado, la acción de la Corte IDH y de los Estados nacionales respectivos, a través principalmente del Poder Judicial y también de otras autoridades públicas, en estas primeras etapas, han seguido el mejor procedimiento racional que existe, que es el procedimiento judicial, puesto que está institucionalizado, es de creación de derecho, garantiza la racionalidad práctica. Procedimiento judicial que necesariamente, según lo desarrollado en este artículo, está vinculado a la ley, a los precedentes judiciales y a la dogmática. Esto permite una reducción considerable de la inseguridad relativa.

\section{SÍNTESIS}

Según lo que hemos expuesto, en el marco diseñado en el capítulo I para la racional e irracionalidad, la Corte IDH y los Estados nacionales respectivos, a 
través de sus jueces y otras autoridades públicas, al realizar el ejercicio del control de convencionalidad, se han ceñido a una actuación racional en cuanto facultad pensante que permite criticar, argumentar, exigir lo incondicionado, encontrar lo mejor que se le ofrece utilizando para ello el procedimiento más adecuado que es el judicial; que le permite garantizar una considerable racionalidad práctica y una reducción mayor de la inseguridad relativa al momento de realizar este ejercicio hermenéutico de control cv. No observándose en todo este estudio algún acto que pueda considerarse carente de razón, falto de racionalidad o irracional.

\section{VII. ÚlTIMAS REFLEXIONES}

No obstante, los sólidos fundamentos precedentes, resulta necesario realizar un último ejercicio. Supongamos dos hechos por un momento: a) Que en el caso Myrna Mack Chang vs. Guatemala ${ }^{87}$ de 25 de noviembre de 2003 el juez Sergio García Ramírez no caviló en su voto razonado, el párrafo 27, que alude al control de convencionalidad. b) Que el pleno de la Corte IDH no realizó la reflexión en el caso Almonacid Arellano y otros vs. Chile ${ }^{88}$ de 26 septiembre de 2006, párrafo 124, que menciona el mismo control de convencionalidad. La pregunta es ¿qué actividad de razonamiento e interpretación debe realizar un juez de un Estado parte -que dispone como fuente de derecho vigente a la $\mathrm{CADH}$ - al momento de resolver un caso de derechos humanos, sin que exista alguna doctrina o mecanismo denominado "control de convencionalidad"? La respuesta es, lo que han hecho los magistrados por innumerables años. Es decir, los jueces van auscultando el derecho, analizando sus fuentes, resolviendo sus posibles antinomias, observando los vacíos; cotejando, comparando una y otra vez las normas de todo el espectro que han reunido y que deben aplicar; ensayando una serie de propuestas que tengan por objeto la defensa y plena vigencia del ejercicio de los derechos y libertades consagrados en los textos normativos nacionales e internacionales. Un ejemplo de esas actividades (guardando las distancias para el caso estudiado), es lo actuado por Sir Edward Coke, en el caso Bonham de $1606^{89}$. Interpretó, estudió modernamente las fuentes y la ley, verificando irracionalidades o contradicciones.

87 Corte IDH, caso Myrna Mack Chang con Guatemala. Sentencia de 25 de noviembre de 2003, voto razonado del juez Sergio García Ramírez, párrafo 27.

88 Corte IDH, Almonacid Arellano y otros con Chile. Sentencia de 26 de septiembre de 2006, párrafo 124.

89 VELÁSQUEZ (1998), p. 139. La ensayista cita parte del fallo: "Aparece en nuestros libros que en muchos casos el common law controla Acts del Parlamento y que a veces los relega a la absoluta nulidad; porque cuando 
Lo mismo en el caso de el Mercader de Venecia, de William Shakespeare. Donde Porcia, en una interpretación integral del Derecho, le hace ver Shylock, su irracionalidad. Situación que no cabe en el derecho ${ }^{90}$. Luego, el juez al construir el fallo -que cabe duda - va a ejecutar una cantidad de operaciones intelectuales infinitas - muchas de ellas- sin saberlo han engarzado, desde hace muchos años, con el denominado ejercicio del control de convencionalidad.

\section{SÍNTESIS}

Aun observando la historia y la literatura, podemos verificar que los jueces han venido practicando una serie de operaciones que se asimilan al denominado control de convencionalidad.

\section{Conclusiones}

La Comunidad jurídica internacional y en especial la interamericana, desde hace por los menos 75 años, han venido, a través de variados instrumentos, difundiendo y protegiendo los derechos humanos.

Esta comunidad jamás ha abandonado su facultad para crear, criticar, reflexionar, en la defensa de los derechos humanos, y ahora está consciente de lo que el trabajo reflexivo puede lograr.

El control de convencionalidad -noción y ejercicio-, ha sido una larga y decantada reflexión. Esto demuestra que la Corte IDH y los tribunales nacionales se han mantenido en una franja de racionalidad. Trabajando con el procedimiento judicial (que al decir de Alexy nos ofrece más seguridad en las decisiones que otros, pues es estructurado racionalmente), su actuar entonces, ha sido, dentro de los marcos históricos, jurídicos y racionales que se espera de un tribunal de derechos humanos.

un Acts del Parlamento se opone al derecho común y a la razón o repugna o es de imposible aplicación, el common law lo controla y se impone sobre tal Acts, anulándolo".

90 Mesa (2012), pp. 30. El Mercader de Venecia de William Shakespeare. El jurista, cita parte de la obra: Pues Porcia expresó que según la ley y la decisión del Tribunal le pertenece a Shylock, una libra de carne de Antonio; pero agrega ella -dirigiéndose a Shylock-, dando una lectura íntegra al derecho y al contrato; el contrato te otorga una libra de su carne. Toma la carne que es lo que te pertenece, una libra exacta; pero si derramas una sola gota de su sangre, tus tierras y tus bienes serán confiscados por el Estado Veneciano, conforme a la ley de Venecia. Puntualizando que siempre sobre nuestras conciencias, nos rondan los límites y los mínimos. 
Control en todo caso, que tiene su origen en el sistema europeo. Luego, si no hubiera sido en el caso Almonacid Arellano, seguramente habría surgido dicho control cv, en años posteriores, en otra causa.

De las críticas y observaciones indicadas, no se vislumbra, luego de pasar todas ellas el tamiz de los requisitos básicos, que puedan seriamente refutar la noción y ejercicio del control cv. El principal argumento, es el hecho que no se sitúan en el derecho internacional de los derechos humanos, sino que lo hacen desde el derecho común o desde el derecho internacional.

Haciendo un símil con Kant, en cuanto que el espacio y el tiempo no son entes sino condiciones propias de nuestra facultad de conocer, a que se someten los objetos que aprehendemos sensorialmente ${ }^{91}$. Habría que decir lo mismo, con el control de convencionalidad, está incorporado en nuestra facultad de conocer, y las normas que se aplican, en los casos que se deben juzgar, deben someterse a dicho control.

En definitiva, el control de convencionalidad -noción y ejercicio- en estas primeras etapas, es una manifestación de la Corte IDH y de los Estados nacionales respectivos que la aplican, de una extendida, profunda y plena racionalidad para la defensa de los derechos humanos.

\section{BiBLIOGRAFÍA CITADA}

Alexy, Robert (2008): Teoría de los derechos fundamentales (Madrid, España. Centro de Estudios Políticos y Constitucionales).

Caballero Ochoa, José Luis (2014): "La protección de los derechos humanos y fundamentales de acuerdo a la Constitución y el Derecho Internacional de los Derechos humanos en México", en: Nogueira Alcalá, Humberto (coordinador). La protección de los Derechos Humanos y fundamentales de acuerdo a la Constitución y el Derecho Internacional de los Derechos Humanos, (Santiago de Chile, Librotecnia) (Santiago de Chile, Librotecnia,) pp. 105 a 120.

Cançado Trindade, Antonio Augusto (2006): El Derecho Internacional de los Derechos Humanos en el Siglo XXI, (Santiago de Chile, Editorial Jurídica de Chile).

(2012): El derecho de acceso a la justicia en su amplia dimensión, (Santiago de Chile, Librotecnia).

91 Torretti (2013), pp. 84-85. 
Carmona, Carla (2015): Wittgenstein. La consciencia del limite (España, editorial, Bonalletra Alcompás, S. L.).

Collí Ek, Víctor Manuel (2015): “De la supremacía literal de la Constitución a la material en el nuevo paradigma jurisprudencial de defensa de derechos en México", en: Anuario de Derecho Constitucional Latinoamericano 2015 (Colombia, Konrad Adenauer Stiftung), pp. 151-174.

Correia, Manuel (2016): “¿Es Aristóteles un pensador contemporáneo?”, en sección Artes y Letras (Santiago, Ediciones El Mercurio S. A.).

Espinosa-SaldaÑa Barrera, Eloy (2014): “Sobre la «Convencialización» del derecho y los derechos en el Perú: ¿̇Alternativa posible y conveniente, o aspiración inalcanzable e incluso discutible?" en: NogUeira AlCALÁ, Humberto (coordinador). La protección de los Derechos Humanos y fundamentales de acuerdo a la Constitución y el Derecho Internacional de los Derechos Humanos, (Santiago de Chile, Librotecnia) (Santiago de Chile, Librotecnia,) pp. 121 a 146.

(2015): "Reflexiones sobre la convencionalización del derecho y el control de convencionalidad en nuestros países, a propósito de lo sucedido en la experiencia peruana", en: Anuario de Derecho Constitucional Latinoamericano 2015 (Colombia, Konrad Adenauer Stiftung), pp. 87-92.

Ferrater Mora, José (2007): Diccionario de Filosofía Abreviado (Buenos Aires, Editorial Sudamericana S. A.).

GaldÁmez Zelada, Liliana (2014): "El valor asignado por la jurisprudencia del Tribunal Constitucional a la jurisprudencia de la Corte Interamericana años 2006-2011", en: Nogueira Alcalá, Humberto (coordinador). La protección de los Derechos Humanos y fundamentales de acuerdo a la Constitución y el Derecho Internacional de los Derechos Humanos (Santiago de Chile, Librotecnia), pp. 287 a 306.

García Pino, Gonzalo (2014): "Preguntas esenciales sobre el control de convencionalidad difuso aplicables a Chile", en: Nogueira Alcalá, Humberto (coordinador). La protección de los Derechos Humanos y fundamentales de acuerdo a la Constitución y el Derecho Internacional de los Derechos Humanos (Santiago de Chile, Librotecnia), pp. 355 a 379.

Gauché Marchetti, Ximena (2014): “Análisis crítico de la Ley No 20.609, que establece medidas contra la discriminación, a la luz del derecho internacional de los derechos humanos y las convenciones de la OEA sobre discriminación de 2013", en: Revista Chilena de Derecho y Ciencia Política (Vol. 5- No 1), pp. 11-58. 
GonZÁlez García, Juan Carlos (2000): Diccionario de Filosofía (Madrid, España. Biblioteca Edaf).

GonZÁlez, Nazario (2002): Los Derechos Humanos en la Historia (México, Alfaomega Grupo Editor S.A. de C. V.)

HABERMAS, Jürgen (1998): Teoría de la acción comunicativa, I. Racionalidad de la acción y racionalización social (España, Taurus editorial).

IńigueZ Manso, Andrea Rosario (2014): "El control de convencionalidad en la CADH y los tribunales chilenos: una tesis de aplicación restrictiva", en: Nogueira Alcalá, Humberto (coordinador). La protección de los Derechos Humanos y fundamentales de acuerdo a la Constitución y el Derecho Internacional de los Derechos Humanos, (Santiago de Chile, Librotecnia) (Santiago de Chile, Librotecnia) pp. 38-394.

Ivanschitz Boudeguer, Bárbara (2014): "Cumplimiento de las sentencias de la Corte Interamericana de Derechos Humanos por parte del Estado de Chile", en: Nogueira Alcalá, Humberto (coordinador). La protección de los Derechos Humanos y fundamentales de acuerdo a la Constitución y el Derecho Internacional de los Derechos Humanos, (Santiago de Chile, Librotecnia) (Santiago de Chile, Librotecnia) pp. 425-456.

KessaL-Wulf, Sibylle (2015): "El Tribunal Constitucional Federal y los tribunales supranacionales: problemas actuales de un sistema multinivel”, en: Anuario de Derecho Constitucional Latinoamericano 2015 (Colombia, Konrad Adenauer Stiftung), pp. 175-190.

MarTínez EstaY, José Ignacio (2014): "Subsidiariedad y margen de apreciación en las relaciones derecho nacional-derecho supranacional. Consideraciones para el diálogo entre la Corte Interamericana de Derechos Humanos y los tribunales nacionales", en: Nogueira AlcalÁ, Humberto (coordinador). La protección de los Derechos Humanos y fundamentales de acuerdo a la Constitución y el Derecho Internacional de los Derechos Humanos, (Santiago de Chile, Librotecnia) pp. 307-344.

Medina Q., Cecilia (1990): Derecho Internacional de los Derechos Humanos (Santiago de Chile, Cecilia Medina, Editora).

Mesa Latorre, Álvaro (2012): “¿Qué hacemos con la sentencia?, en: "Ponencia en el Congreso de Justicia de Policía Local Araucanía”, (Pucón 2012).

MuÑOZ GajARDO, Sergio (2014): "El estándar de convencionalidad y el principio pro homine", en: Nogueira Alcalá, Humberto (coordinador). La protección de los Derechos Humanos y fundamentales de acuerdo a la Constitución y el De- 
recho Internacional de los Derechos Humanos, (Santiago de Chile, Librotecnia) (Santiago de Chile, Librotecnia), pp. 149 a 247.

NASH Rojas, Claudio (2010): "La protección internacional de los derechos humanos: reglas comunes", en: NASH Rojas, Claudio y MujICA Torres, Ignacio (editores). Derechos Humanos y Juicio Justo (Santiago de Chile, Red Interamericana de Formación en Gobernabilidad y Derechos Humanos, Colegio de las Américas- Colam, Organización Interamericana Universitaria), pp. 58-98. (2012 a): Comentarios al trabajo de Víctor Bazán: El control de convencionalidad: incógnitas, desafíos y perspectivas”, en: BAZAN, Víctor y NASH, Claudio (editores). Justicia Constitucionaly Derechos Fundamentales. El control de Convencionalidad (Colombia, Konrad Adenauer Stiftung) pp. 57-71.

(2012 b): Derechos Internacional de los Derechos Humanos en Chile. Recepción y aplicación en el ámbito interno (Santiago, Universidad de Chile, Facultad de Derecho, Centro de Derechos Humanos).

(2014): "Cumplimiento de las resoluciones internacionales sobre derechos humanos en casos contenciosos. Estado actual y proyecciones institucionales", en: Nogueira Alcalá, Humberto (coordinador). La protección de los Derechos Humanos y fundamentales de acuerdo a la Constitución y el Derecho Internacional de los Derechos Humanos, (Santiago de Chile, Librotecnia) (Santiago de Chile, Librotecnia) pp. 457-479.

Nogueira Alcalá, Humberto (2008): Derechos fundamentales y garantías constitucionales (Santiago de Chile. Editorial Librotecnia), tomo II.

(2014): "Sistema interamericano de protección de derechos humanos, control de convencionalidad y aplicación por parte de las jurisdicciones nacionales", en: Nogueira Alcalá, Humberto (coordinador). La protección de los Derechos Humanos y fundamentales de acuerdo a la Constitución y el Derecho Internacional de los Derechos Humanos, (Santiago de Chile, Librotecnia) (Santiago de Chile, Librotecnia) pp. 395-421.

NúÑEz Donald, Constanza (2014): Control de Convencionalidad: Teoría y aplicación en Chile. Memoria para optar al grado de Licenciada en Ciencias Jurídicas y Sociales (Santiago, Universidad de Chile, Facultad de Derecho).

Pedrals G. de Cortázar, Antonio (2014): Fundamentos de Teoría General del Derecho (Santiago de Chile, Librotecnia).

Pérez Luño, Enrique Antonio (2010): Derechos Humanos, Estado de Derecho y Constitución (Madrid, España. Tecnos) 10 edición. 
Real Academia de la Lengua (2001): Diccionario de la Lengua Española (España, Editorial Espasa Calpe S.A.) $22^{\circ}$ edición.

RaWLs, John (2006): Teoría de la Justicia (México, Fondo de Cultura Económica). Revista de Derecho y Jurisprudencia (1991): Jurisprudencia. Tomo LXXXVIII, No 2 y No 3, secc. IV. pp. 56 y 106.

Rivera Santivañez, José Antonio (2014): "La protección de los derechos humanos y fundamentales en el Estado plurinacional de Bolivia”, en: Nogueira AlcalÁ, Humberto (coordinador). La protección de los Derechos Humanos y fundamentales de acuerdo a la Constitución y el Derecho Internacional de los Derechos Humanos, (Santiago de Chile, Librotecnia) pp. 25-57.

Rojas Betancourth, Danilo (2015): "Control de convencionalidad en Colombia. Entre el control de la Convención y su aplicación “, en: Anuario de Derecho Constitucional Latinoamericano 2015 (Colombia, Konrad Adenauer Stiftung), pp. 113-140.

SAGÜÉS, Néstor Pedro (2014): “Derechos constitucionales y derechos humanos. De la Constitución Nacional a la "Constitución convencionalizada» en: NogUeIRA AlCalÁ, Humberto (coordinador). La protección de los Derechos Humanos y fundamentales de acuerdo a la Constitución y el Derecho Internacional de los Derechos Humanos (Santiago de Chile, Librotecnia), pp. 15-23.

(2015): "Notas sobre el control ejecutivo de convencionalidad", en: Anuario de Derecho Constitucional Latinoamericano 2015 (Colombia, Konrad Adenauer Stiftung), pp. 141-149.

Salmon, Elizabeth (2010): "La relación entre el derecho internacional de los derechos humanos y el ordenamiento jurídico estatal", en: NASH ROJAS, Claudio y Mujica Torres, Ignacio (editores). Derechos Humanos y Juicio Justo (Santiago de Chile, Red Interamericana de Formación en Gobernabilidad y Derechos Humanos, Colegio de las Américas-Colam, Organización Interamericana Universitaria), pp. 99-158.

SÁNCHEZ, Camilo (2010): "Introducción al sistema interamericano de protección de los derechos humanos", en: NASH Rojas, Claudio y MujiCa Torres, Ignacio (editores). Derechos Humanos y Juicio Justo, (Santiago de Chile, Red Interamericana de Formación en Gobernabilidad y Derechos Humanos, Colegio de las Américas - Colam, Organización Interamericana Universitaria), pp 11-57.

SolÉ, Juan (2015): Kant. El giro copernicano en la filosofía (España, editorial, Bonalletra Alcompás, S. L.). 
(2016): Mirando Al Cielo. Breve historia de la Astronomía (España, editorial, Bonalletra Alcompás, S. L.).

Torretti, Roberto (2013): Manuel Kant. Estudio sobre los fundamentos de la filosofía critica (Santiago de Chile, Ediciones, Universidad Diego Portales).

Vio Grossi, Eduardo (2015): "Jurisprudencia de la Corte Interamericana de Derechos Humanos: ¿del control de convencionalidad a la supranacionalidad?" en: Anuario de Derecho Constitucional Latinoamericano 2015 (Colombia, Konrad Adenauer Stiftung), pp. 93-112.

\section{DOCUMENTOS EN FORMATO ELECTRÒNICO}

Aguilar Cavallo, Gonzalo (2013): "El control de convencionalidad: Análisis en Derecho Comparado", en: Revista Direito GV, Sao Paulo 9(2), pp. 721-754, [fecha de consulta: 5 de diciembre de 2016]. [Disponible en: http://www. scielo.br/scielo.php?script=sci_isoref\&pid=S180824322013000200015\&ln $\mathrm{g}=\mathrm{en} \& \mathrm{t} \operatorname{lng}=\mathrm{es}]$.

CARBOnell, Miguel (S/A): "Introducción general al Control de Convencionalidad" [fecha de consulta: 7 de noviembre de 2016]. Disponible en: https://archivos. juridicas.unam.mx/www/bjv/libros/7/3271/11.pdf.

Contreras, Pablo (2014): "Control de Convencionalidad, Deferencia Internacional y Discreción Nacional en la Jurisprudencia de la Corte Interamericana de Derechos Humanos", en: Revista Ius et Praxis, (Año 20, No 2, 2014), pp. 235-274, [fecha de consulta: 2 de diciembre de 2016]. [Disponible en: http://www.scielo.cl/pdf/iusetp/v20n2/art07.pdf.

CORTE IDH (2016): "Cuadernillo de Jurisprudencia de la Corte Interamericana de Derechos Humanos No 7. Control de Convencionalidad" [fecha de consulta: 2 de diciembre de 2016]. [Disponible en http://www.corteidh.or.cr/sitios/ libros/todos/docs/controlconvencionalidad8.pdf].

Hitters, Juan Carlos (2009): "Control de Constitucionalidad y Control de Convencionalidad. Comparación (Criterios fijados por la Corte Interamericana de Derechos Humanos)", en: Estudios Constitucionales, Universidad de Talca, (Año 7, No 2, 2009), pp. 109-128, [fecha de consulta: 5 de diciembre de 2016]. [Disponible en http://www.scielo.cl/scielo.php?script=sci_arttext\&pi $\mathrm{d}=$ S0718-52002009000200005].

Nogueira Alcalá, Humberto (2013): "El control de convencionalidad y el diálogo interjurisdiccional entre tribunales nacionales y Corte Interamericana de Derechos Humanos", en: Estudios Constitucionales, Universidad de Talca 
(ReDCE. Año 10. Núm. 19, enero-junio/2013), pp. 57-140 [fecha de consulta 5 de diciembre de 2016]. [Disponible en: http://www.scielo.cl/pdf/estconst/ v10n2/art03.pdf].

(2015): "El principio pro homine o favor persona en el derecho internacional y en el derecho interno como regla de interpretación y regla de preferencia normativa", [fecha de consulta 6 de diciembre de 2016]. [Disponible en: http://cmjusticiaconstitucional.com/wp-content/uploads/2015/08/Principiofavor-persona-o-pro-homine-2015_-13-agosto-2015.-Humberto-NogueiraAlcala-.pdf].

Velásquez Rizo, Ana María (1998): “El Caso Bonham. Supremacía Constitucional”. [fecha de consulta 12 de enero de 2017]. [Disponible en rcientificas.uninorte. edu.co/index.php/derecho/article/download/2749/1852].

Verbic, Francisco (2012): "Control de Convencionalidad en el Sistema Interamericano de Protección de Derechos Humanos. Principales Características y Algunos Apuntes sobre su Aplicación en el Ordenamiento Jurídico Argentino" [fecha de consulta: 7 de noviembre de 2016]. [Disponible en: http://www. academia.edu/3617712/Control_de_Convencionalidad_en_el_Sistema_Interamericano_de_Protecci\%C3\%B3n_de_Derechos_Humanos._Principales_Caracter\%C3\%ADsticas_y_Algunos_Apuntes_sobre_su_Apl].

\section{NORMAS JURÍDICAS CITADAS}

Constitución Política de la República de Chile. Diario Oficial 22 de septiembre de 2005.

Convención Americana sobre Derechos Humanos denominada "Pacto San José de Costa Rica”. Diario Oficial 5 de enero de 1991.

Ley No 18.127 sobre cuentas corrientes bancarias y cheques. Diario Oficial, 7 de octubre de 1982.

Convención sobre el Derecho de los Tratados y su anexo. Diario Oficial, 22 de junio de 1981.

\section{JURISPRUDENCIA CITADA}

Opinión consultiva OC-2/82 (1982): Corte Interamericana de Derechos Humanos. 24 de septiembre de 1982. El efecto de las reservas sobre la entrada en vigencia de la Convención Americana sobre Derechos Humanos solicitada por Comisión Interamericana de Derechos Humanos, serie A No 02. 
Myrna Mack Chang vs. Guatemala (2003): Corte Interamericana de Derechos Humanos, 25 de noviembre de 2003. Fondo, reparaciones y costas. Serie C, No 101.

Almonacid Arellano y otros vs. Chile (2006): Corte Interamericana de Derechos Humanos, 26 de septiembre de 2006. Excepciones preliminares, fondo, reparaciones y costas. Serie C, No 154. 